\title{
Acute Stroke Patients Treated with Stent Retrievers in Carotid "T" Occlusions Have Improved Recanalization and Outcome
}

\author{
Trent H. Orton, Cheemun Lum, Mohammed Alhazzaa, Howard Lesiuk, \\ Dar Dowlatshahi, Marlise P. dos Santos, Daniela Iancu
}

\begin{abstract}
Background: Recanalization rates and patient outcomes in acute occlusion of the carotid terminus have previously been poor. The use of stent-retrievers has resulted in better recanalization and patient outcomes. We sought to compare outcomes in patients treated with stent-retrievers to outcomes in older techniques. Methods: We retrospectively compared a stent-retriever cohort to a historical cohort. We evaluated recanalization rates and good outcomes (defined as mRS $<2$ at 30 days or 10 point drop in NIHSS). Results: There were twenty patients treated with stent-retrievers versus nine without. The recanalization rate in patients treated with stent retrievers was significantly higher than that of other modalities $(90 \%$ vs $33 \%, \mathrm{p}=0.004)$. Good outcomes were significantly higher in the stent retriever cohort $(70 \%$ vs $22 \%, \mathrm{p}=0.041)$. Conclusion: The use of stent-retrievers in patients with carotid "T" occlusions shows promise in comparison to older techniques. A randomized trial comparing stent-retriever therapy to IV thrombolysis is warranted to determine the efficacy of this new generation of devices.
\end{abstract}

RÉSUMÉ: Les patients traités par thrombectomie mécanique lors d'un accident vasculaire cérébral aigu dû à une occlusion de la carotide en T présentent une meilleurs recanalisation et un meilleur résultat. Contexte: Le taux de recanalisation et les résultats chez les patients atteints d'une occlusion aiguë de la carotide en $\mathrm{T}$ se sont avérés médiocres par le passé. La thrombectomie mécanique a permis de réaliser une meilleure recanalisation et de meilleurs résultats chez ces patients. Nous avons comparé les résultats obtenus chez des patients traités par thrombectomie mécanique à ceux de patients traités par des techniques conventionnelles. Méthode: Nous avons comparé rétrospectivement une cohorte de patients traités par thrombectomie mécanique à une cohorte de patients ayant reçu le traitement usuel par le passé. Nous avons étudié le taux de recanalisation et les bons résultats (définis comme étant mRS $\leq 2,30$ jours après le traitement ou une chute de 10 points au score NIHSS). Résultats: Vingt patients ont été traités par thrombectomie mécanique et 9 ont reçu le traitement conventionnel. Le taux de recanalisation chez les patients traités par thrombectomie mécanique était significativement plus élevé que celui observé chez les patients traités autrement (90\% comparé à 33\%; p =0,004). Le taux de bons résultats était significativement plus élevé dans la cohorte de patients ayant subi une thrombectomie mécanique (70\% comparé à $22 \% ; \mathrm{p}=0,041)$. Conclusion: La thrombectomie mécanique chez les patients atteints d'une occlusion de la carotide en $\mathrm{T}$ semble prometteuse par rapport aux techniques plus anciennes. Ces constatations justifient la tenue d'une étude randomisée comparant la thrombectomie mécanique et la thrombolyse par voie IV afin de déterminer l'efficacité de cette nouvelle génération de dispositif médical.

Keywords: Stroke, endovascular, embolectomy, stent-retriever

doi:10.1017/cjn.2014.109

Can J Neurol Sci. 2014; 41: 709-713

Carotid terminus occlusions ("T" occlusions) have a dismal prognosis in the setting of acute stroke, with a natural history that carries greater than $50 \%$ mortality. ${ }^{1}$ The poor clinical outcomes are likely related to the occlusion of circle of Willis collaterals and prior limited strategies to remove large clot volumes. ${ }^{2,3}$ Previous endovascular recanalization strategies in carotid $\mathrm{T}$ occlusions such as pharmaceutical thrombolysis, angioplasty, earlier generation mechanical retrieval and thromboaspiration had variable results. ${ }^{1,2,4-7}$

Stent retrievers have been shown to improve recanalization rates, morbidity and mortality in acute large vessel stroke (internal carotid artery [ICA], M1 or M2 branches of the middle cerebral artery [MCA] or the vertebrobasilar artery) (Figure 1). ${ }^{8-12}$ However, data are lacking regarding outcomes in carotid $\mathrm{T}$ occlusions treated with stent retrievers.
Recent interventional trials failed to show improved clinical outcomes when compared with intravenous (IV) thrombolysis alone. ${ }^{13}$ However, these trials largely preceded the introduction of stent retrievers. Given the improved recanalization rates with stent retrievers and the large volume of clot often encountered

From the Ottawa Stroke Research Group, Ottawa Hospital Research Institute (THO, CL, MA, HL, DD, MPdS, DI), University of Ottawa, Diagnostic Imaging-Neuroradiology Section (THO, CL, HL, MPdS, DI), Ottawa, ON, Canada; University of OttawaDepartment of Medicine (Neurology) (MA, DD), Ottawa, ON, Canada; King Fahad Medical City (MA), Riyadh, Kingdom of Saudi Arabia.

Received June 30, 2014. Final Revisions Submitted October 15, 2014. Correspondence to: Cheemun Lum, University of Ottawa Faculty of Medicine, Department of Medical Imaging, The Ottawa Hospital-Civic Campus, 1053 Carling Avenue, Ottawa, Ontario, Canada K1Y 4E9. Email: chlum@ottawahospital.on.ca 
in patients with carotid $\mathrm{T}$ occlusion, we sought to evaluate the outcomes of patients with acute anterior circulation $\mathrm{T}$ occlusions treated at a single academic stroke referral centre.

\section{MeTHODS}

\section{Study Population}

Institutional ethics review board approval was obtained. We retrospectively reviewed consecutive patients that underwent intra-arterial therapy for acute thromboembolic stroke between January 2010 and April 2013 at an academic stroke referral centre. The study interval that was chosen as our prior cohort of acute stroke patients had been previously analyzed. ${ }^{14} \mathrm{We}$ obtained patient data from electronic health records and clinical chart reviews. The clinical data were reviewed independently by a clinical stroke neurology fellow trained in National Institutes of Health Stroke Scale (NIHSS) assessment with experience in managing acute stroke codes and administration of IV tissue plasminogen activator (tPA).

All patients presenting with acute stroke in our institution have an unenhanced head CT. Patients with a clinical suspicion of proximal vessel occlusion have a CT angiography (CTA) of the neck and brain performed. Depending on scanner availability, CT perfusion is also performed simultaneously with CTA of the brain.

At our institution, the following criteria are applied to determine patient suitability for endovascular stroke therapy in the anterior circulation:

1. Patients with acute strokes presenting $<6$ hours from onset or wake-up strokes with salvageable brain suspected on imaging defined as <one-third CA territory hypodensity on unenhanced CT or a time-to-peak to cerebral blood volume mismatch of $>25 \%$ on CT perfusion.

2. NIHSS $>7$.

3. CT showing no intracerebral hemorrhage and Alberta Stroke Program Early CT score $\geq 7$.

4. Endovascular therapy can be initiated within 6 hours of symptom onset for an anterior circulation thrombus. In the case of wake-up strokes, patients with CT Alberta Stroke Program Early CT $\geq 7$ can also receive this therapy.

Our inclusion criteria for this study were the following:

1. CTA demonstrating carotid T occlusion.

2. Patient fulfilling criteria for endovascular therapy for acute anterior circulation stroke.

\section{Endovascular Treatments}

Endovascular treatment of acute stroke has been performed at our institution since 2000. A variety of intra-arterial techniques have been used, including: intra-arterial tPA, balloon angioplasty, microcatheter clot maceration, mechanical retrievers (MERCI, Concentric Medical, Mountain View, CA), thromboaspiration (Penumbra System, Penumbra, Inc., Alameda, CA) and stent retrievers (Solitaire AB, Covidien/ev3, Dublin, Ireland; Trevo, Concentric Medical, Mountain View, CA).

Informed consent was obtained from the patient or next of kin. We performed all cases under conscious sedation unless there were respiratory or cardiovascular concerns necessitating general anaesthesia. After femoral arterial access was obtained, a $2000 \mathrm{U}$ heparin bolus is usually given unless IV tPA had already been administered. Cerebral angiography was performed and a decision was made on what treatment approach to employ at the discretion of the neurointerventionalist.

Stent retrievers, such as the Solitaire and Trevo devices used in this study, combine clot retrieval and proximal flow arrest with aspiration performed during clot retrieval. An $8 \mathrm{Fr}$ balloon aspiration catheter (MERCI) was placed into the ICA above the carotid bulb. Under roadmap guidance, a microcatheter (Prowler Select Plus, Codman Neurovascular, Codman \& Shurtleff, Inc., Raynham, MA; or Trevo microcatheter, Concentric Medical) over a 0.010- or 0.014-inch wire was advanced into the MCA distal to the $\mathrm{T}$ occlusion. A small test injection of contrast was performed to confirm adequate placement for stent deployment. Either a Solitaire AB (off-label use, before availability of flow-restoration [FR]) or a Trevo stent retriever was advanced into the M1 segment and deployed. A guide catheter angiogram was performed to determine if temporary clot bypass had been achieved. Five minutes later, after proximal balloon inflation for flow arrest, we retrieved the stent retriever under aspiration with a $60-\mathrm{mL}$ syringe attached to the side port of the balloon guide. We visually inspected the stent to determine if the clot had been extracted. If there was no back-bleeding in the balloon guide after stent retrieval, we removed the guide catheter to evaluate if the clot was lodged in the guide.

\section{Variables of Interest}

We obtained patient baseline characteristics including demographic information (age, gender), stroke risk factors (hypertension, diabetes, dyslipidemia, coronary arterial disease, peripheral vascular disease, internal carotid stenosis, prior stroke, atrial fibrillation), baseline NIHSS scores and intravenous tPA use.

Baseline non-contrast CT (NCCT), CTA and angiographic images and reports were reviewed retrospectively and thrombus location was confirmed by a single interventional neuroradiologist (12 years' experience) blinded to the clinical outcome.

Outcome variables obtained included percentages of both groups for recanalization rate, mortality, symptomatic intracranial hemorrhage (Eastern Cooperative Acute Stroke Study III definition ${ }^{15}$ ), good outcomes, time to recanalization (puncture to stent deployment) and length of hospital stay in each group.

We defined two groups of good clinical outcomes:

1. modified Rankin Score (mRS) at 30 days less than or equal to 2 .

2. Either an $\mathrm{mRS} \leq 2$ at 30 days or a 10-point reduction in the NIHSS at 30 days after treatment.

We used a similar outcome metric compared with other studies; however, we chose a more stringent criteria for improved NIHSS. ${ }^{10}$ Recanalization was graded using Thrombolysis in Cerebral Infarction criteria. ${ }^{16}$ Successful recanalization was defined as achieving Thrombolysis in Cerebral Infarction grade 2 (a or b) or higher. ${ }^{9}$

\section{Statistical Analysis}

Baseline characteristics of both groups were compared with a Fisher's exact test for the categorical variables (gender, use of IV tPA, hypertension, dyslipidemia, smoking, atrial fibrillation, ICA stenosis, diabetes, prior stroke/transient ischemic accident, peripheral vascular disease, coronary arterial disease) and a 
Table 1: Baseline characteristics

\begin{tabular}{|c|c|c|c|}
\hline & Stent $(n=20)$ & Multimodal $(n=9)$ & Significance \\
\hline Age, median (IQR) & $74(58-83)$ & $65(60-77)$ & $\mathrm{p}=0.772$ \\
\hline Gender ( $\%$ male $)$ & 60 & 33 & $\mathrm{p}=0.184$ \\
\hline NIHSS, median (IQR) & $18(17-20)$ & $19(18-20)$ & $\mathrm{p}=0.633$ \\
\hline IV tPA (\%) & 60 & 78 & $\mathrm{p}=0.431$ \\
\hline Hypertension (\%) & 45 & 67 & $\mathrm{p}=0.427$ \\
\hline Diabetes (\%) & 10 & 33 & $\mathrm{p}=0.287$ \\
\hline Dyslipidemia (\%) & 55 & 77 & $\mathrm{p}=0.412$ \\
\hline $\mathrm{CAD}(\%)$ & 15 & 33 & $\mathrm{p}=0.339$ \\
\hline Prior stroke/TIA (\%) & 15 & 0 & $\mathrm{p}=0.532$ \\
\hline $\operatorname{PVD}(\%)$ & 10 & 22 & $\mathrm{p}=0.568$ \\
\hline Smoking $(\%)$ & 20 & 22 & $\mathrm{p}=1.000$ \\
\hline AFIBB $(\%)$ & 45 & 33 & $\mathrm{p}=0.694$ \\
\hline Severe ICA stenosis (\%) & 20 & 33 & $\mathrm{p}=0.642$ \\
\hline
\end{tabular}

$\mathrm{AFIBB}=$ atrial fibrillation $\mathrm{CAD}=$ coronary artery disease; $\mathrm{IQR}=$ interquartile range $\mathrm{PVD}=$ peripheral vascular disease;

$\mathrm{TIA}=$ transient ischemic accident.

Mann-Whitney test for continuous, nonparametric variables (age, baseline NIHSS score).

Categorical outcome variables in both groups were also compared with Fisher's exact tests (recanalization rates, good clinical outcome rates, mortality, symptomatic intracranial hemorrhage). Continuous outcome variables (length of stay, time to recanalization) in both groups were compared with a Mann-Whitney test. A p value $<0.05$ was considered statistically significant. All statistical analysis was performed with SPSS 20 software (IBM, Armonk, NY).

\section{RESULTS}

There were 70 patients, of which 57 had anterior circulation strokes. There were 44 patients treated with stent retrievers, of which 42 had anterior circulation strokes. Our study population consisted of 29 patients with carotid T occlusions: 20 carotid T patients (48\% of anterior circulation strokes) identified between August 2011 to April 2013 (group 1) compared with 9 (36\%) between July 2010 and November 2011. In group 2, two patients had only intra-arterial tPA, three were treated with thromboaspiration with Penumbra only, two were primarily treated with angioplasty and intra-arterial tPA, one was treated with Penumbra and intra-arterial tPA and one was treated with Penumbra followed first by a rescue attempt with the Solitaire stent retriever. There was an equal proportion of stentretriever cases treated with Solitaire and Trevo. Six of $10(60 \%)$ Solitaire cases were treated with a 6-mm diameter stent and four (40\%) were treated with a 4-mm diameter stent.

There were no significant differences in the baseline characteristics (Table 1). The median age in group 1 was 74 and 65 in group 2. IV tPA was used in $60 \%$ of patients in group 1 and $88 \%$ of patients in group 2. The baseline NIHSS scores were 18 and 19 in groups 1 and 2, respectively.

Table 2 summarizes the difference in outcomes between the two groups. The recanalization rates in patients treated with stent retrievers was significantly higher than other modalities $(90 \%$ vs $33 \%, \mathrm{p}=0.004)$. There was a trend towards good outcomes in patients treated with stent retrievers (44\% vs $11 \%, \mathrm{p}=0.19)$. When a drop in NIHSS $>10$ was also considered, good outcomes were significantly higher in the stent retriever cohort $(70 \%$ vs $22 \%, \mathrm{p}=0.041)$. The time to recanalization was shorter in the stent retriever group (66 vs 98 minutes, $\mathrm{p}=0.06$ ). There was a

\section{Table 2: Imaging and clinical outcomes}

\begin{tabular}{|c|c|c|c|}
\hline & Stent $(\mathbf{n}=\mathbf{2 0})$ & Multimodal $(\mathbf{n}=9)$ & Significance \\
\hline Proportion recanalized (\%) & 90 & 33 & $\mathrm{p}=0.004$ \\
\hline Onset to puncture (h) & 3.7 & 3.8 & $\mathrm{p}=0.931$ \\
\hline Puncture to recanalization (min) [median (IQR)] & $66(49-70)$ & $98(71-120)$ & $\mathrm{p}=0.06$ \\
\hline Good outcome $1(30$-day $\mathrm{mRS} \leq 2)(\%)$ & 44 & 11 & $\mathrm{p}=0.193$ \\
\hline Good outcome 2 (30-day mRS $\leq 2$ or $\downarrow$ NIHSS of 10 ) (\%) & 70 & 22 & $\mathrm{p}=0.041$ \\
\hline Mortality (\%) & 15 & 33 & $\mathrm{p}=0.339$ \\
\hline Symptomatic ICH (\%) & 0 & 11 & $\mathrm{p}=0.310$ \\
\hline Length of stay (days) [median (IQR)] & $13(5-21)$ & $13(6-30)$ & $\mathrm{p}=0.357$ \\
\hline
\end{tabular}

$\mathrm{ICH}=$ intracerebral hemorrhage; $\mathrm{IQR}=$ interquartile range. 


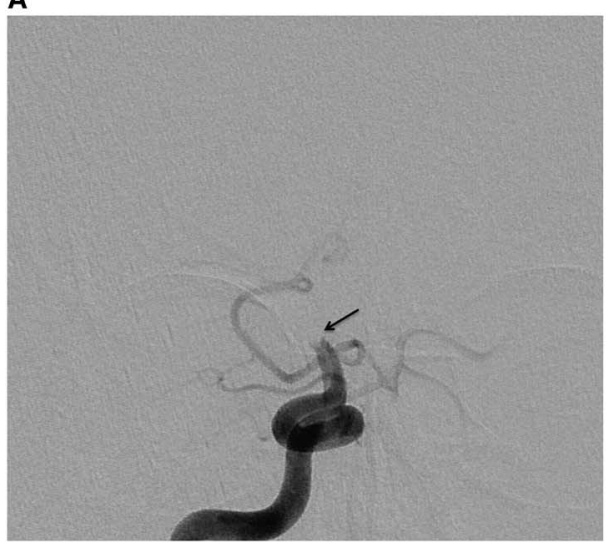

B

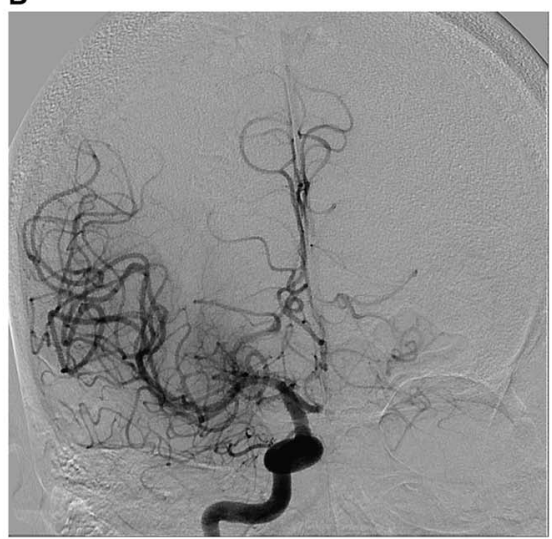

Figure 1: (A) Anteroposterior view from a catheter angiogram demonstrates an internal carotid artery T occlusion (arrow). Post stent-retriever angiogram shows complete recanalization.

tendency toward lower mortality rates $(15 \%$ vs $33 \%, \mathrm{p}=0.338)$ and lower rates of symptomatic intracerebral hemorrhage (0 vs $11 \%, \mathrm{p}=0.310$ ) in the stent-retriever group.

\section{Discussion}

Recanalization rates in acute stroke are strongly associated with improved functional outcomes and reduced mortality. ${ }^{17}$ The immediate aim of acute stroke treatment is recanalization of the occluded vessel and reperfusion of the ischemic brain. Currently the only proven therapy in acute stroke is intravenous thrombolysis performed within 4.5 hours from stroke onset. ${ }^{15,18}$ Large vessel occlusions are difficult to recanalize, likely because of large volumes of clot. When the occlusion involves an internal carotid terminus, the recanalization rates with IV tPA are low at $4.4 \% .^{17}$ This has prompted the use of endovascular therapies that have improved recanalization rates up to $60-77 \%$, depending on the clot location. ${ }^{13,17}$ However, previous randomized controlled trials failed to show benefit in functional outcome with the use of additional endovascular therapy compared with standard IV therapy. $^{13,19}$

Stent retrievers in acute large-vessel stroke have shorter recanalization times, improved recanalization rates and better clinical outcomes compared with other endovascular devices. ${ }^{9,10,20-24}$ The $48 \%$ of patients in our study with carotid T occlusions was higher than other reported series (16-32\%). ${ }^{5,7}$ Our stent-retriever recanalization rate was significantly higher than our prior cohort of carotid $\mathrm{T}$ occlusions treated with multimodality therapy. This higher rate of recanalization appears to be consistent regardless of the type or diameter of stent retriever used. Our results with stent retrievers also have improved recanalization rates compared with other published series of T occlusions. ${ }^{1,2,4-7}$ We had $44 \%$ good outcomes (70\% when ten-point drop in NIHSS was included) as evaluated by $\mathrm{mRS} \leq 2$. This compares favorably with prior studies of terminus occlusions, with good outcomes $(\mathrm{mRS} \leq 2)$ seen in a proportion of patients ranging from 16 to $33 \% .^{1,2,4-7}$ In a large cohort of ICA occlusions, Fischer et al reported good outcomes in only $16 \%$ of carotid T occlusions. Recently, Yoon, et al evaluated their experience with stent retrievers in a cohort of 26 patients with intracranial ICA occlusion. ${ }^{25}$ They demonstrated $77 \%$ recanalization and $39 \%$ good outcomes; however, there was no comparison group in this study. Kwak et al reported $79 \%$ recanalization and
$43 \%$ good outcomes in a subset of 14 ICA terminus occlusions. ${ }^{26}$ More recently, good outcomes ranging from 20 to $24 \%$ have been reported in larger series. ${ }^{27,28}$ Our study and other recent trials provide promising preliminary data ${ }^{9,10}$; however, the efficacy of these new devices compared with IV tPA remains to be demonstrated in a randomized trial.

Our study has several limitations: the data were retrospectively collected, historical controls were used and the cohorts were nonrandomized and retrospectively analyzed. Subsequently, the study was subject to potential confounders. In particular, the cohort of non-stent retriever cases had smaller numbers and was performed earlier (from July 2010 to November 2011). The stentretriever cases, on the other hand, were performed from December 2011 to March 2013. Although no changes in management were noted to occur during this period, an unknown confounder in the treatment algorithm is theoretically possible. Our proportion of good outcomes was statistically significant when criteria similar to the Diffusion and Perfusion Imaging Evaluation for Understanding Stroke Evolution-2 study ${ }^{29}$ were used; however, it was not statistically significant when only $\mathrm{mRS}$ was considered. This may be due to our small sample size. Finally, as in other trials, our clinical follow-up was limited to 30 days. $^{29,30}$

\section{CONCLuSION}

In patients presenting with acute stroke secondary to carotid $\mathrm{T}$ occlusions, the use of stent retrievers were associated with improved recanalization rates, recanalization times and neurological outcomes compared with a historical cohort treated with other endovascular strategies. These data are encouraging given the large clot volumes and prior poor clinical results previously experienced with endovascular therapy in acute carotid T occlusion. A randomized trial comparing stent-retriever therapy to IV tPA is warranted to determine the efficacy of this new generation of devices.

\section{REFERENCES}

1. Jansen O, von Kummer R, Forsting M, Hacke W, Sartor K. Thrombolytic therapy in acute occlusion of the intracranial internal carotid artery bifurcation. AJNR Am J Neuroradiol. 1995;16:1977-86.

2. Lin R, Vora N, Zaidi S, et al. Mechanical approaches combined with intra-arterial pharmacological therapy are associated with higher 
recanalization rates than either intervention alone in revascularization of acute carotid terminus occlusion. Stroke. 2009;40:2092-7.

3. Saqqur M, Uchino K, Demchuk AM, et al. Site of arterial occlusion identified by transcranial Doppler predicts the response to intravenous thrombolysis for stroke. Stroke. 2007;38:948-54.

4. Beck C, Cheng B, Krutzelmann A, et al. Outcome of MRI-based intravenous thrombolysis in carotid-T occlusion. J Neurol. 2012;259:2141-6.

5. Fischer U, Mono ML, Schroth G, et al. Endovascular therapy in 201 patients with acute symptomatic occlusion of the internal carotid artery. Eur J Neurol. 2013;7:1017-24.

6. Flint AC, Duckwiler GR, Budzik RF, Liebeskind DS, Smith WS. Mechanical thrombectomy of intracranial internal carotid occlusion: pooled results of the MERCI and Multi MERCI Part I trials. Stroke. 2007;38:1274-80.

7. Georgiadis D, Oehler J, Schwarz S, Rousson V, Hartmann M, Schwab S. Does acute occlusion of the carotid T invariably have a poor outcome? Neurology. 2004;63:22-6.

8. Espinosa de Rueda M, Parrilla G, Zamarro J, Garcia-Villalba B, Hernandez F, Moreno A. Treatment of acute vertebrobasilar occlusion using thrombectomy with stent retrievers: initial experience with 18 patients. AJNR Am J Neuroradiol. 2013;5:1044-8.

9. Nogueira RG, Lutsep HL, Gupta R, et al. Trevo versus Merci retrievers for thrombectomy revascularisation of large vessel occlusions in acute ischaemic stroke (TREVO 2): a randomised trial. Lancet. 2012;380:1231-40.

10. Saver JL, Jahan R, Levy EI, et al. Solitaire flow restoration device versus the Merci Retriever in patients with acute ischaemic stroke (SWIFT): a randomised, parallel-group, non-inferiority trial. Lancet. 2012;380:1241-9.

11. Brekenfeld C, Schroth G, Mordasini P, et al. Impact of retrievable stents on acute ischemic stroke treatment. AJNR Am J Neuroradiol. 2011;32:1269-73.

12. Fesl G, Patzig M, Holtmannspoetter M, et al. Endovascular mechanical recanalisation after intravenous thrombolysis in acute anterior circulation stroke. Cardiovasc Intervent Rdiol. 2012; 35:1326-31.

13. Broderick JP, Palesch YY, Demchuk AM, et al. Endovascular therapy after intravenous t-PA versus t-PA alone for stroke. N Engl J Med. 2013;368:893-903.

14. Alhazzaa M, Murphy A, Lum C, Dos Santos MP, Lesiuk H, Bussiere M. Angioplasty as an adjuvant therapy for the treatment of acute ischemic stroke. Can J Neurol Sci. 2011;38:593-9.

15. Hacke W, Kaste M, Bluhmki E, et al. Thrombolysis with alteplase 3 to 4.5 hours after acute ischemic stroke. $\mathrm{N}$ Engl J Med. 2008;359:1317-29.

16. Higashida RT, Furlan AJ, Roberts H, et al. Trial design and reporting standards for intra-arterial cerebral thrombolysis for acute ischemic stroke. Stroke. 2003;34:e109-37.
17. Bhatia R, Hill MD, Shobha N, et al. Low rates of acute recanalization with intravenous recombinant tissue plasminogen activator in ischemic stroke: real-world experience and a call for action. Stroke. 2010;41:2254-8.

18. Tissue plasminogen activator for acute ischemic stroke. The National Institute of Neurological Disorders and Stroke rt-PA Stroke Study Group. N Engl J Med. 1995;333:1581-7.

19. Ciccone A, Valvassori L, Nichelatti M, et al. Endovascular treatment for acute ischemic stroke. N Engl J Med. 2013;368:904-13.

20. Castano C, Dorado L, Guerrero C, et al. Mechanical thrombectomy with the Solitaire $\mathrm{AB}$ device in large artery occlusions of the anterior circulation: a pilot study. Stroke. 2010;41:1836-40.

21. Costalat V, Machi P, Lobotesis K, et al. Rescue, combined, and stand-alone thrombectomy in the management of large vessel occlusion stroke using the Solitaire device: a prospective 50patient single-center study: timing, safety, and efficacy. Stroke. 2011;42:1929-35.

22. Miteff F, Faulder KC, Goh AC, Steinfort BS, Sue C, Harrington TJ. Mechanical thrombectomy with a self-expanding retrievable intracranial stent (Solitaire AB). AJNR Am J Neuroradiol. 2011;32(6):1078-81.

23. Mpotsaris A, Bussmeyer M, Loehr C, Oelerich M, Buchner H, Weber W. Mechanical thrombectomy in severe acute stroke: preliminary results of the Solitaire stent. J Neurol Neurosurg Psychiatry. 2012;83:117-8.

24. Roth C, Papanagiotou P, Behnke S, et al. F. Stent-assisted mechanical recanalization for treatment of acute intracerebral artery occlusions. Stroke. 2010;41:2559-67.

25. Yoon YH, Yoon W, Jung MY, Yim NY, Kim BC, Kang HK. Outcome of mechanical thrombectomy with Solitaire stent as firstline intra-arterial treatment in intracranial internal carotid artery occlusion. Neuroradiology. 2013;55:999-1005.

26. Kwak JH, Zhao L, Kim JK, Park S, Lee DG, Shim JH, et al. The outcome and efficacy of recanalization in patients with acute internal carotid artery occlusion. AJNR Am J Neuroradiol. 2014;35:747-53.

27. Frahm D, Wunderlich S, Schubert MI, Poppert H, Kleine JF, Prothmann. Mechanical thrombectomy in acute occlusion of the carotid-T. Clin Neuroradiol. 2014 [Epub ahead of print].

28. Liebeskind DS, Flint AC, Budzik RF, Xiang B, Smith WS. Carotid I's, L's and T's. J Neurointervent Surg. 2014 [Epub ahead of print].

29. Lansberg MG, Straka M, Kemp S, et al. MRI profile and response to endovascular reperfusion after stroke (DEFUSE 2): a prospective cohort study. Lancet Neurol. 2012;11:860-7.

30. Marks MP, Olivot JM, Kemp S, et al. Patients with acute stroke treated with intravenous tPA 3-6 hours after stroke onset: correlations between MR angiography findings and perfusion- and diffusion-weighted imaging in the DEFUSE study. Radiology. 2008;249:614-23. 